\title{
USE of INNOVATIVE TECHNOLOGY for IRRIGATION in UTTARAKHAND HILLS in INDIA
}

\author{
Kiran Kumar Dangwal and Archana Rani \\ School of Engineering, G.D. Goenka University, Gurgaon, Haryana, India
}

\begin{abstract}
Energy security, today, is of greatest concern for a sustainable future. For convenience, using newer technologies, we are accelerating the consumption of depleting resources viz. Oil, timber and fossil fuel. Nuclear and hydro power has inherent implications in maintaining ecological balance. Nature itself provides abundance of green renewable energy to meet all human requirements. Centuries old practices have been forgotten. This paper includes the latest solar and wind energy utilisation techniques. Augmentation of centuries old techniques for irrigation have also been explored. It is towards this end that the flexible modular concept is suggested for irrigation in remote hilly regions. People from Uttarakhand hills in India have abandoned cultivation all together and mostly migrated to plains in search of alternate livelihood. This is disturbing the demography of the entire region and further cascading the problem of overpopulation in cities. The village land is lying virtually abandoned. The locals are confining themselves to very small scale farming by tapping meagre available water. Lifting of water from low level for terrace cultivation by way of pumps etc is not economical. This paper aims to suggest a concept of utilising the natural energy sources like gravitational flow, barometric pressure, wind and solar energy. As complementary to this effort the farmers need to learn the importance of rain harvesting. For saving of water they need to resort to drip and capillary irrigation. This integration of old and new techniques for a sustainable solution is critically explored.
\end{abstract}

Keywords: Drip irrigation, green energy, rain water harvesting.

\section{INTRODUCTION}

People in Uttarakhand hills have abandoned cultivation all together, due to paucity of water for irrigation. They have mostly migrated to plains in search of alternate livelihood. This is disturbing the demography of the entire region and further cascading the problem of overpopulation in cities. The village land is lying virtually abandoned. The locals are confining themselves to very small scale farming by tapping meagre available water. Lifting of water from low level for terrace cultivation by way of pumps etc is not economical. This paper aims to suggest a concept of utilising the natural energy sources like gravitational flow, barometric pressure, wind and solar energy. For judicious use of water they need to resort to drip and capillary irrigation. By adopting the modified old technology it will be possible to arrest migration.

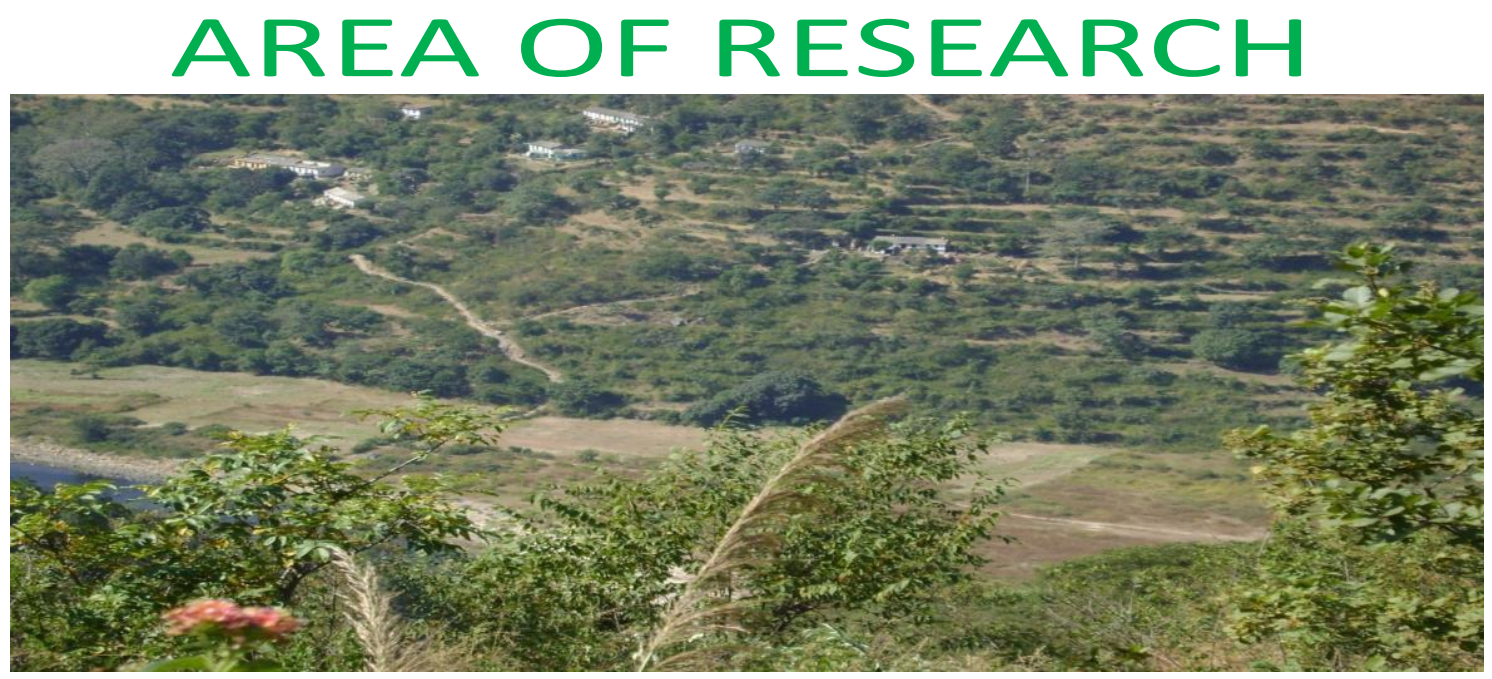

\section{SYSTEM CONFIGURATION}

Earlier generations have been using the natural energy to their advantage. Water wheel, solar heating devices, hydraulic rammer systems and wind energy configuration have been in use for centuries. With the advancement of technology, however, these devices have been upgraded and made more efficient. Therefore, in remote areas, these can be easily made use of to obtain better results and output. The relevant source of information is taken from various publications and also marked with reference wherever applicable. The proposed system envisages no use of existing electric supply or any type of fuel pump. The energy is solely obtained from natural sources which are available in abundance locally. The present system has a modular design for irrigation in 2 hectares of land in hilly areas. 
ICAASET-2021, 20-21 May, 2021, K.R. Mangalam University, Gurugram

International Journal of Technical Research \& Science (Special Issue) ISSN No.:2454-2024 (online)

\subsection{Spiral Wheel Pump}

Water wheel has been in use for ages to lift water from a running water source to a higher elevation for farming purposes. Linear motion of running water is simply converted into rotating motion. For this purpose a current of 3 knots is sufficient to rotate the wheel. With further refining, over the years, the same rotary motion was utilised and led to the discovery of spiral pump. The wheel was replaced with a wound pipe. While moving with the force of running water the pipe picks up water and air alternately. The compressed air is utilised for lifting the water to a much higher elevation. For higher discharge a number of these units can be installed along the length of the running water source. Use of non return valve can further enhance its efficiency [8]. For the purpose of fabrication now stronger and lighter materials are available in the market. This will ensure that more efficient and economic models can be made.

\section{SPIRAL PUMP WORKING}

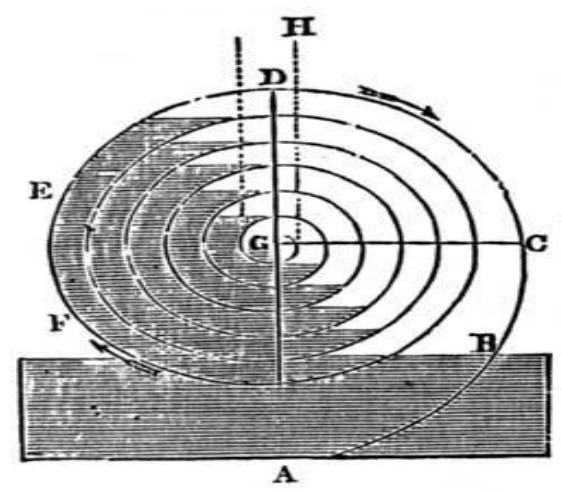

160 feet long 1 inch dia 3900 glpd at 40 feet head. Water current of 2 feet per second or more required

\subsection{Solar Energy System}

Energy of Sun has been harnessed for heating purpose since time immemorial. With the discovery of photo voltaic cells a micro-grid can be created [2]. The micro-grid can be combined with the wind energy grid thus providing adequate power. A suitable battery bank can also be charged along side when power is not consumed elsewhere [3]. A micro grid of 10-20 KW will be adequate for this purpose. Owing to the low level of atmospheric pollution in the hilly region of Uttarakhand and bright sun shine, the Sun energy is available in abundance. Setting up of solar farms will also promote extensive utilisation of barren and abundant land. To encourage use of this technology most governments are providing subsidy even up to $80 \%$ of the total cost.

\subsection{Wind Energy}

Wind mills have been in use for centuries for getting a rotary motion. The power achieved by this device was utilised for grinding or operating a conveyer belt or a water pumping system. With discovery of motor the same natural energy can be utilised for generating power. To generate electricity we need a wind speed of minimum 9 knots. By using suitable gear ratios an rpm of 1500 can be achieved. By combining adequate numbers of such turbines, one can create a micro-grid [9]and also link it with main grid with the help of a Grid Tied Inverter(GTI) to feed surplus power back to the main grid. The electrical power thus generated can be conveniently utilised for operating water pumps. In the hilly terrain of Uttarakhand, the required wind speed is always available. In the undulating profile of sub-Himalayan region of Uttarakhand, these wind farms can be installed in the hill tops. Perpetual and strong winds are always available there.

\subsection{Running River Pump}

This uses the same principle that of a spiral pumps on a running water. The running water enters a spiral coil with the rotation of the wheel with the force of the current [4]. Alternately it keeps taking air in each rotation. Because of the continuous, rotary motion the air gets compressed and pushes the water to a higher elevation. The water can be lifted to an elevation of 80 feet vertically [5]. For horizontal transfer of water the same device can take water to a few kilometres. For greater discharge the size of the device can be suitably modified or these can be installed in tandem. This is also a static mechanical device and can be manufactured locally at a very low cost [7]. The device is maintenance free and uses no fuel or electricity and runs on the gravitational flow of water. These devices can be designed in various sizes depending on the availability of water in different seasons. The river pump is easy to fabricate, assemble and transport to any location. 
ICAASET-2021, 20-21 May, 2021, K.R. Mangalam University, Gurugram

International Journal of Technical Research \& Science (Special Issue) ISSN No.:2454-2024 (online)

RIVER PUMP OPERATION

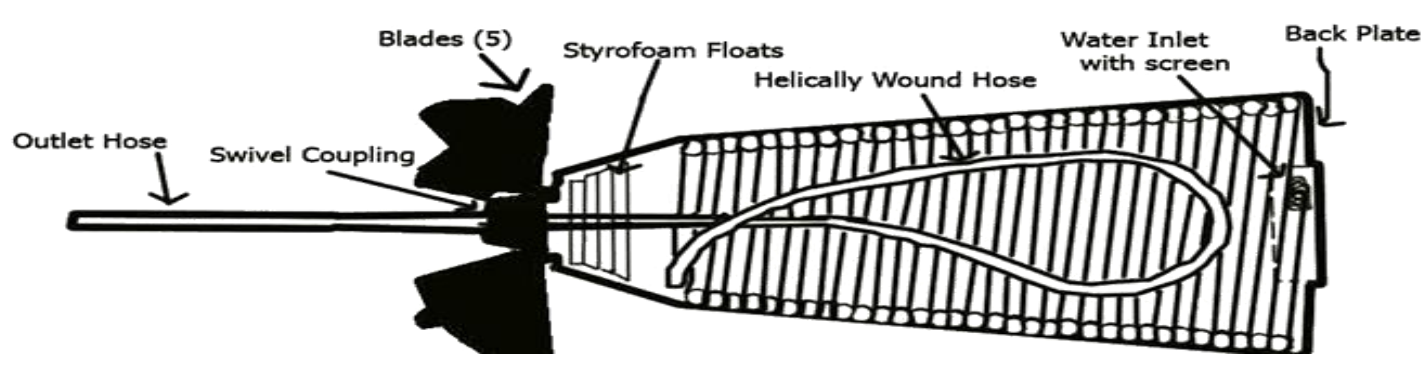

\subsection{Hydraulic Ram}

Gravity has been used in lifting of water with the help of hydraulic hammer by the device called hydram. In hilly areas, water stored at higher elevation is made to fall to a lower level. The falling water with its potential energy pushes water from a lower level along a lesser diameter pipe to a higher level [6]. With the use of non return valve the water is not allowed to drain back to lower level. By repetitive action the water is thus stored at higher elevation than it originally dropped from. This is a purely static mechanical device and very easy to fabricate. The device has been used extensively used before the advent of modern devices for lifting of water. There is some amount of wastage through over flow valve but by deploying these in tandem the same can be reutilised. Using proper configuration water can be lifted up to an elevation of 500 feet. With the use of lighter and stronger material available now for improved efficiency. This operates for 24 hours a day in all seasons without maintenance. Air pressure chamber can be designed according to the desired output.

\section{HYDRAM WORKING}

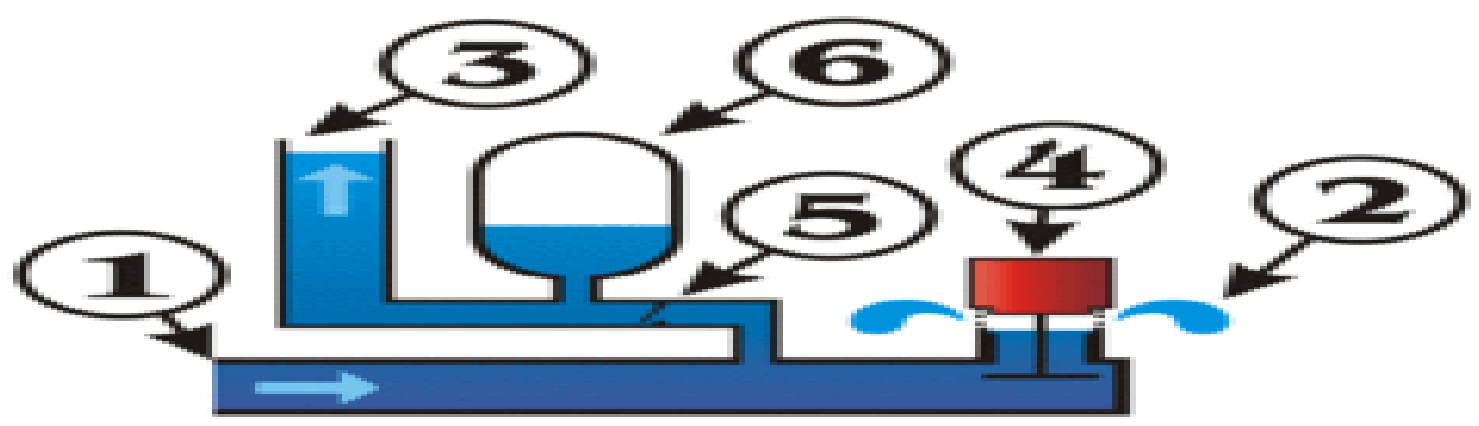

\subsection{Using Capillary Lift}

How do the trees lift the water from ground? This is possible with capillary action which is due to barometric pressure. By the same action you notice the seepage on the walls from the ground. This happens due to intermolecular cohesion, adhesion and surface tension. At Mean Sea Level a water column can rise to a height of 34 feet by capillary action. The barometric pressure keeps falling marginally as the altitude increases. The same principle can be utilised for lifting water for irrigation purpose. If you bunch together a large number of capillary tubes made of fibre glass, and put them in a casing, then the water from a lower level can be lifted to a height of 34 feet at MSL vertically. At inclined position the water can be transported to a greater horizontal distance.

\section{CAPILLARY LIFT}

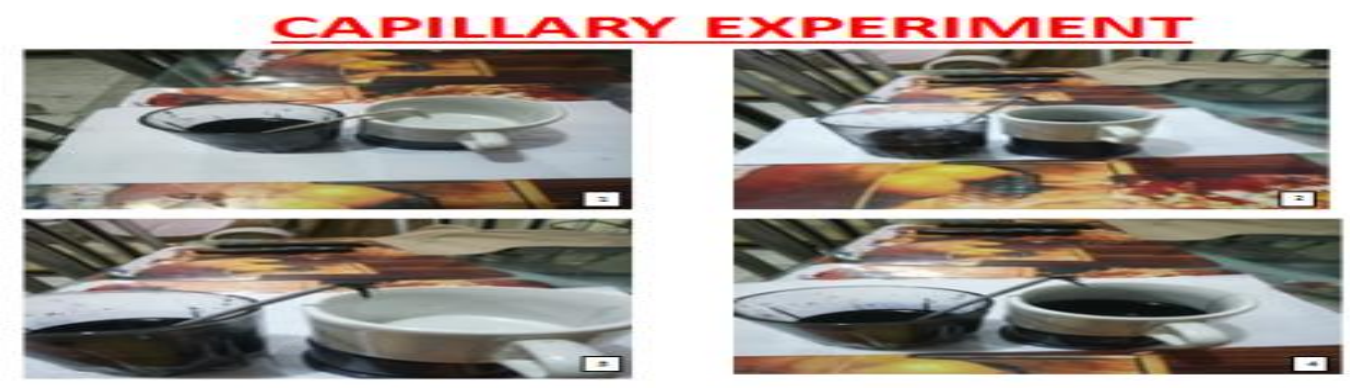

The next task is to extract water from the highest point. This can be transferred with the help of a porous material. One can use a sponge, fibre or cotton material. The water thus lifted so far is stored in another

DOI Number: https://doi.org/10.30780/specialissue-ICAASET021/013

pg. 67

Paper Id: IJTRS-ICAASET2021-013

@2017, IJTRS All Right Reserved, www.ijtrs.com 
container. From this stage another bunch of capillary tubes are utilised for the next stage. By a repetitive process the water can be lifted to any elevation. The head of the bunch of capillary tubes can be kept slightly below the natural capillary lift elevation at the particular altitude. Using the same technique, underground water can also be extracted from a depth of 34 feet. A bore well can be dug and the bunch of capillary inserted into it. Similarly along a dry river bed number of such arrangement can be installed for greater discharge. This is purely a use of natural energy phenomenon of capillary lift, without using a pump on conventional energy.

Using the same principle, underground or sub soil can be lifted to the surface. Multiple casing with a bunch of capillary tubes can be utilised for the desired output. It virtually amounts to pulling the ground water to a higher level by making use of the barometric pressure.

\subsection{Micro-grid}

A micro-grid of $10 \mathrm{KW}$ can be conveniently installed in a village in the hills. Government is also giving huge subsidy for the purpose. The micro-grid will also have a bank of batteries. This requires a small wind farm and adequate number of PV solar panels. This will be useful when the natural energy sources are not available in their full potentials. The micro-grid may be connected to the main grid, if existing, through a Grid Tie Inverter (GTI).This will also supplement the main grid when not being used for irrigation water supply.

\section{AC MICRO GRID}

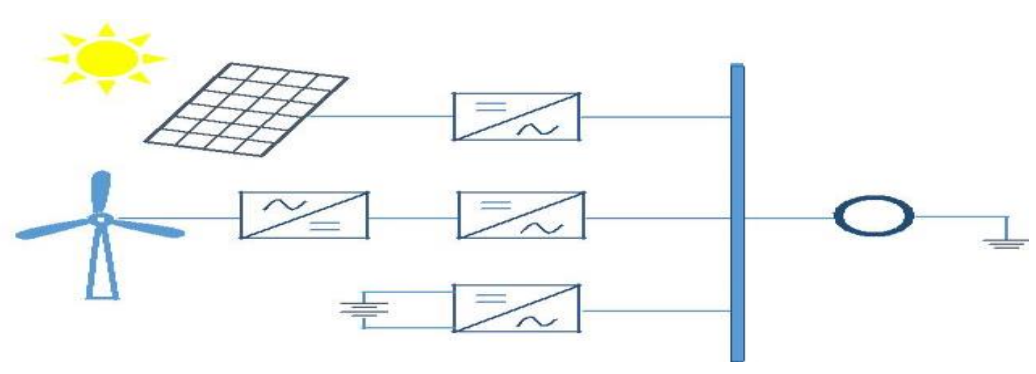

\subsection{Controller}

To monitor the configuration functioning, there is a need for installing a electronic controller. The water lifted by various means will be stored at higher level for subsequent use for irrigation in terrace cultivation. The controller monitors various parameters. The wind speed is observed for wind farm and water current for running river pump and spiral pump. The aim is to utilise naturally available resources and conserve the power

\section{SCHEMATIC DIAGRAM}

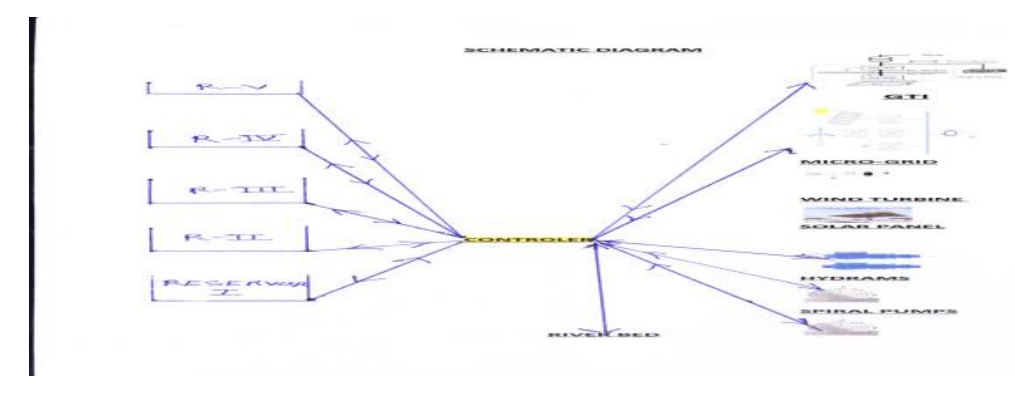

\section{EFFICIENT METHODS OF FARMING}

Most conventional methods of irrigation result in enormous wastage of water. Plants require only a very small percentage of water for its botanical growth. Rest of the water is lost in evapotranspiration depending upon the local conditions and type of soil. Newer techniques as under can be incorporated for judicious and intelligent application of water to the plant root. Sufficient water is available in hilly areas but care is not taken to trap rain water and store it for prolonged use.

\subsection{Drip Irrigation System}

It is up to the farmers how best to utilise the scares available water. Instead of soaking the entire field for irrigation it is more efficient to provide the water near the plant root[1]. Otherwise much of the water is wasted in evaporation or simply flows down the slope. It is a well known fact that the plant actually requires only one percent of the water calculated by conventional methods for its botanical growth. In drip irrigation the water is provided directly at the root of the plant. In the cultivated field a network of perforated pipes are laid. These are connected to a source or a storage tank from which the water flows in a controlled manner directly at the root of the plant. For plains there may be a need for pumping the water in the network of laid out pipes. For hills the 
ICAASET-2021, 20-21 May, 2021, K.R. Mangalam University, Gurugram International Journal of Technical Research \& Science (Special Issue) ISSN No.:2454-2024 (online)

gravity flow can be easily utilised. The water source is kept at a higher elevation from which the water flows down by gravity.

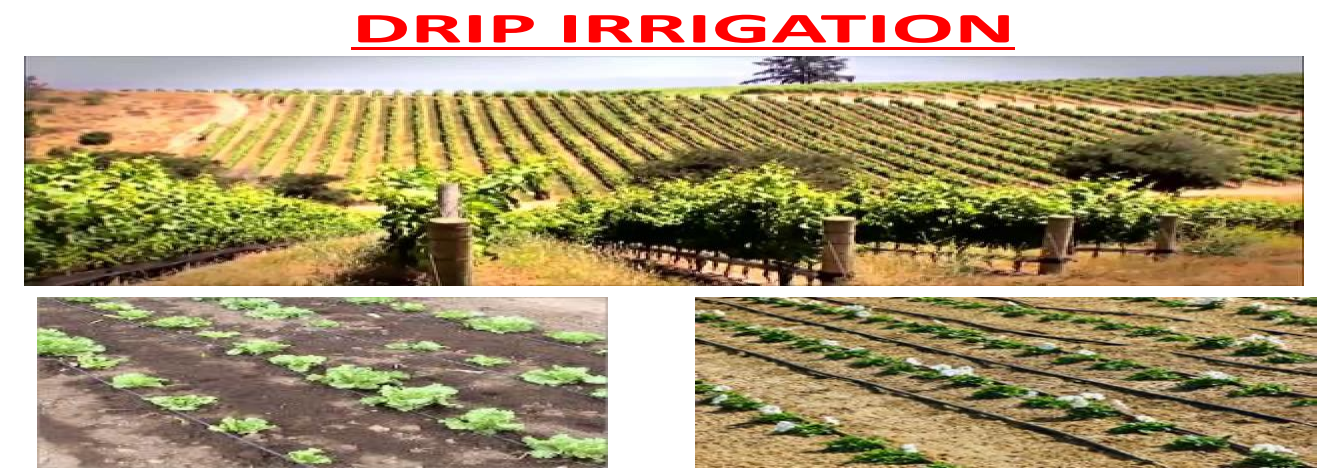

\subsection{Harvesting the Rain Water}

Whatever rain water falls in the hilly areas, most of it drains out in the slopes and ruts. There is a need to catch this water and use for irrigation. Ponds are made to trap this water at different elevations. Apart from this, the rain water can be used for recharging the ground water. Once the ground water level rises in the bore wells, it can be dug for lifting the water to the surface using capillary lift. Recharging can be done by digging shallow pits along the run of the ruts. Ruts can also be made by channelizing the water along the desired path. Every village in the hills has a spring water source. To increase the discharge of the spring, pits are dug along the run of the rain water on the upstream side. A perforated drum is inserted in the pit and covered on top. These drums will recharge the ground water and increase the discharge of the spring. Waste water from the spring needs to be accumulated in a pond.

\subsection{Capillary Water Delivery System}

Capillary system requires even lesser water than the drip system of irrigation. Here the plant takes the water as per its botanical needs. Because of difference in root pressure the plant absorbs the water by capillary action. The source is kept at a lower elevation and the plant is fed from below. The elevation difference depends on the barometric pressure in the given area. Gravity flow is downwards and capillary lift is upwards. This saves the energy for lifting the water to the plant level. Water source can be below the cultivated terrace level.

\section{WATER REQUIREMENT}

Various crops in different climatic condition require different quantity of water for their growth. Even same crop at different locations may require different quantity of water. It is a complex calculation where experience of usage over a period of time takes precedence. It also depends on the type of soil and the method of cultivation. However, some academicians have attempted to formulise the concept, with whatever credit they deserve. Prominent amongst them is the Penman Equation [10] to great approximation.

$$
\mathrm{ET}_{\mathrm{o}}=\frac{0.408 \Delta\left(\mathrm{R}_{\mathrm{n}-\mathrm{G}}\right)+\gamma \frac{900}{\mathrm{~T}+273} \mathrm{u}_{2}\left(\mathrm{e}_{\mathrm{s}}-\mathrm{e}_{\mathrm{a}}\right)}{\Delta+\gamma\left(1+0.34 \mathrm{u}_{2}\right)}
$$

Where: $\mathrm{ET}_{\mathrm{o}}=$ reference evapotranspiration $\left[\mathrm{mm}\right.$ day-1], $\mathrm{R}_{\mathrm{n}}=$ net radiation at the crop surface [MJ $\mathrm{m}-2$ day-1], $\mathrm{G}$ $=$ soil heat flux density [MJ $\mathrm{m}-2$ day-1], $\mathrm{T}=$ air temperature at $2 \mathrm{~m}$ height $\left[{ }^{\circ} \mathrm{C}\right], \mathrm{u}_{2}=$ wind speed at $2 \mathrm{~m}$ height $[\mathrm{m} s-1], \mathrm{e}_{\mathrm{s}}=$ saturation vapour pressure $[\mathrm{kPa}], \mathrm{e}_{\mathrm{a}}=$ actual vapour pressure $[\mathrm{kPa}], \mathrm{e}_{\mathrm{s}}-\mathrm{e}_{\mathrm{a}}=$ saturation vapour pressure deficit $[\mathrm{kPa}], \mathrm{D}=$ slope vapour pressure curve $\left[\mathrm{kPa}{ }^{\circ} \mathrm{C}-1\right], \mathrm{g}=$ psychometric constant $\left[\mathrm{kPa}{ }^{\circ} \mathrm{C}-1\right]$. Even some software like CROPWAT 8,0 has also been developed for simulation to some approximation. Evapotranspiration (ET) is the sum of evaporation and plants transpiration to the ambient atmosphere. It is expressed in millimetres $(\mathrm{mm})$ per unit time, which may be minute, day, hour, month or the duration of plant life. It varies from plant to plant and place to place. It is the water lost by the plant to the atmosphere. It depends on the plant growth stage, percentage of soil cover, solar radiation, relative humidity, ambient temperature and wind. Transpiration is more pronounced in light, higher temperature and prevailing wind. As relative humidity (RH) rises, transpiration drops and vice-versa. It can be compared with human perspiration. It is also dependant on wind speed which takes away the moisture from the plant. Higher the wind speed more is the water loss. Vapour pressure deficit, the difference between ambient vapour pressure and the plant vapour pressure, also plays a role. More the deficit, more is the water loss.

\section{SAMPLE DESIGN}

Considering 2 hectares of cultivable land as total surface area, converted from the terrace type fields at different levels, the requirement of water is approximately $50 \mathrm{k}$ glpd of water during the peak demand season. This is an average land holding in one typical village of Uttarakhand hills. This requirement can be met by installing 5 spiral pumps, 5 running river pumps, 15 hydrams and 6 electric motors of 5 HP running on micro-grid. 100 solar 
ICAASET-2021, 20-21 May, 2021, K.R. Mangalam University, Gurugram

International Journal of Technical Research \& Science (Special Issue) ISSN No.:2454-2024 (online)

panels of $1 \mathrm{KW}$ each and 20 wind turbines of $5 \mathrm{KW}$ each are required for setting up the micro-grid. The total cost of these items works out to INR 25 Lakhs.

\subsection{Spiral Pump Discharge Calculations}

$\mathrm{D}=\mathrm{h}_{1}=$ Outer most coil diameter and head,

$\mathrm{H}=$ Delivery head, $\mathrm{n}=$ number of coils, $\mathrm{D}=$ pipe diameter, $\quad \mathrm{h}_{\mathrm{n}}=$ head $_{\text {inn }}{ }^{\text {th }}$ coil

Boyle's Law: $P_{1} \times V_{1}=P_{n} \times V_{n}$

$\mathrm{P}_{1}=\mathrm{P}_{\mathrm{atm}}+\mathrm{D}, \quad \mathrm{V}_{1}=$ airvolumefirstoroutercoil $\mathrm{P}_{\mathrm{n}}=\mathrm{P}_{\mathrm{atm}}+\mathrm{HV}_{\mathrm{n}}=$ airvolumelastorinnercoil

$\mathrm{V}_{1}=\pi \times\left(\frac{1}{2} \mathrm{~d}\right)^{2} \times \mathrm{D} \quad \mathrm{V}_{\mathrm{n}}=\pi \times\left(\frac{1}{2} \mathrm{~d}\right)^{2} \times \mathrm{h}_{\mathrm{n}}$

Given: $H, D \& d$, find $h_{n}$ andn, To find $h_{n}: P_{1} \times V_{1=} P_{n} \times V_{n}$

$\left(\mathrm{P}_{\mathrm{atm}}+\mathrm{D}\right) \times \pi \times\left(\frac{1}{2} \mathrm{~d}\right)^{2} \times \mathrm{D}=\left(\mathrm{P}_{\mathrm{atm}}+\mathrm{H}\right) \times \pi \times\left(\frac{1}{2} \mathrm{~d}\right)^{2} \times \mathrm{h}_{\mathrm{n}}$

Therefore: $\mathrm{h}_{\mathrm{n}}=\left(\mathrm{P}_{\mathrm{atm}}+\mathrm{D}\right) \times \mathrm{D} /\left(\mathrm{P}_{\mathrm{atm}}+\mathrm{H}\right)$

To find $\mathrm{n}: \mathrm{n} \times\left(\mathrm{D}+\mathrm{h}_{\mathrm{n}}\right) / 2=\mathrm{H}$, Therefore : $\mathrm{n}=2 \mathrm{H} /\left(\mathrm{D}+\mathrm{h}_{\mathrm{n}}\right)$

ILLUSTRATION:

Assume : $\mathrm{H}=60 \mathrm{ft}, \quad \mathrm{D}=\mathrm{h}_{1}=8 \mathrm{ft}$, Find: $\mathrm{h}_{\mathrm{n}}$ and $\mathrm{n}$

$\mathrm{h}_{\mathrm{n}}=\left(\mathrm{P}_{\mathrm{atm}}+\mathrm{D}\right) \times \mathrm{D} /\left(\mathrm{P}_{\mathrm{atm}}+\mathrm{H}=(34+8) \times \frac{8}{34+60}, \mathrm{~h}_{\mathrm{n}}=3.4 \mathrm{ft}\right.$

$\mathrm{N}=2 \mathrm{H} /\left(\mathrm{D}+\mathrm{h}_{\mathrm{n}}\right)=2 \times \frac{60}{8+3.4}=10.6, \mathrm{~N}+20 \% \mathrm{~N}=12.7$ coils

5.2 Discharge Parameters

\subsubsection{Water Requirement}

$>$ Land area for irrigation $=2$ hectare $=4.94$ acres

$>$ Nominal water required per day $=200 \mathrm{k} 1$ trs $/$ day $=50 \mathrm{k}$ glpd

\subsubsection{Configuration Output}

$>$ Spiral pump stage I, $8 \mathrm{ft}$ wheel dia, $160 \mathrm{ft}$ length $\& 11 / 4$ in diameter $=6 \mathrm{k}$ glpd

$>$ River Pump stage I, RP-100 model $=2 \mathrm{~K}$ glpd

\subsubsection{Cost Analysis}

$>$ Minimum no of spiral pumps $=12 / 4=3$ Nos $(45000 /=)$

$>$ Minimum no of River pumps $=12 / 2=3$ Nos $(60000 /=)$

$>$ Spiral pump stage II (wind mill driven $)=3 \operatorname{Nos}(45000 /=)$

$>$ Hydrams in tandem $=5 \times 2=10$ Nos $(60000 /=)$

$>$ Electric Motors 5 HP each to give $24 \mathrm{k}$ glpd $=3$ Nos ( $60000 /=)$

\subsubsection{Microgrid}

$>$ PV Panels with $1 \mathrm{KW}$ output each $=50$ Nos ( 1.5 Lakhs)

$>$ Wind Turbines with $5 \mathrm{KW}$ output each $=10$ Nos ( 1.5 lakhs)

(Note: with diversity factor and availability of Sun/Wind for 8 hours/day)

(Cost for one integrated model is 6 Lakhs for $12.5 \mathrm{glpd}$ discharge. Therefore cost for $50 \mathrm{glpd}$ for 2 hectares of land comes to approximately $\underline{\mathbf{2 5} \text { Lakhs }}$

\section{CONCLUSION}

It is amply illustrated from above discussions and calculations that a typical 2 hectares of land in a village can be easily irrigated by installing innovative new technology with a cost of $170000 \$$ in isolation. These integrated systems can serve as a modular design.For sustainable development of irrigation in Uttarakhand hills, it is imperative to employ this innovative technology. Initial installation cost may appear to be high but amortization can be achieved in 5-6 years. Farming by use of fuel pumps and electric supply is neither sustainable nor economical in the long run. The primary aim is to reverse the migration over a period of time. The said configuration is designed for a typical village. If more and more villages are clubbed together with the modular design then it will become cost effective. Development in rural pockets will also contribute to the overall development of the region. The proposed items of the configuration are also not readily available in the market. This will lead to many start ups for mass manufacturing of these components of the system. This in turn will generate employment and over all economic prosperity of the region.

\section{REFERENCES}

[1] Arya, C.K., Purohit, R.C., Dashora, L.K., Singh, P.K. and Mahesh Kothari. 2017. Performance Evaluation of Drip Irrigation Systems. Int. J. Curr. Microbiol. App. Sci. 6(4): 2287-2292.

[2] Maher, P. and Smith, N. 2001. Pico Hydro Village Power: A Practical Manual for Schemes Up to $5 \mathrm{~kW}$ in Hilly Areas. $2^{\text {nd }}$ Edition- Intermediate Technology Publications.

[3] Martin, A., Brian, K. and Sam, A. 2010. Remote Community Electrification in Sarawak, Malaysia. Renewable Energy, 35 (7): 1609-1613.

[4] Ortimer, G. H. and Annabel, R. 1984. he Coil Pump - Theory and Practice. Journal of Hydraulic Research, 22(1): 9-22.

[5] Peter, R. 1979. “A Morgan New Water Pump: Spiral Tube”. The Zimbabwe Rhodesia Science News, 13(18): 179- 180. 
ICAASET-2021, 20-21 May, 2021, K.R. Mangalam University, Gurugram

International Journal of Technical Research \& Science (Special Issue) ISSN No.:2454-2024 (online)

[6] Shuaibu, N.M. 2007. Design and Construction of a Hydraulic Ram Pump. Leonardo Electronic Journal of practices and Technologies, 11: 59-70.

[7] Stuckey A.T. and Wilson E.M. 1980. "The Stream-powered Monomeric Pump". Proceeding of the institute of Civil Engineers Conference on Appropriate Technology in Civil Engineering, London, 105108.

[8] Tailor Peter. 2005. "The Spiral Pump, a High Lift, Slow Turning Pump", Retrieved April 6, 2011.

[9] Williams, A.A. and Simpson, R. 2009. Pico Hydro - Reducing Technical Risks for Rural Electrification. Renewable Energy, 34 (8), 1986-1991.

[10] Journal of Hydrology, Volume 331, Issues 3-4, 15 December 2006, Pages 690-702.

AUTHORS PROFILE

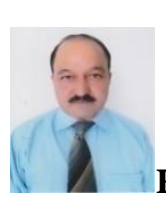

Kiran kumar Dangwal is BSc (PCM) from Agra university, BTech (Electrical Engineering) from CME Pune and MTech (Power apparatus and Systems) from IIT Delhi. Presently pursuing PhD in multidisciplinary engineering subject. He has extensive practical experience in all branches of engineering. He has 30 years of teaching experience. He had been a Director of a new international class engineering college for four years. He has also been a Director of a group of institutions for over one year. He is a Chartered Engineer (CE) and Fellow of the Institution of Engineers (FIE)

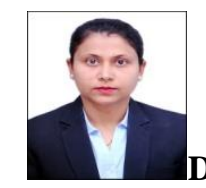

Dr Archana Rani is assistant professor in ECE, School of Engineering, GD Goenka University at Gurugram. She is BTech, MTech and PhD in the same subject from renowned colleges and Institutes in Delhi NCR \& Chandigarh. She has over 13 years of teaching and research experience at Delhi NCR and Pune. She has published more than 15 research papers on the same subject in prestigious journals. 